\title{
Chemical Pressure
}

\author{
Andreas Hauser*, Nahid Amstutz, Sandra Delahaye, Asmaâ Sadki, Sabine Schenker, \\ Regula Sieber, and Mohamed Zerara
}

\begin{abstract}
The physical and photophysical properties of three classic transition metal complexes, namely $\left[\mathrm{Fe}(\mathrm{bpy})_{3}\right]^{2+},\left[\mathrm{Ru}(\mathrm{bpy})_{3}\right]^{2+}$, and $\left[\mathrm{Co}(\mathrm{bpy})_{3}\right]^{2+}$, can be tuned by doping them into a variety of inert crystalline host lattices. The underlying guest-host interactions are discussed in terms of a chemical pressure.
\end{abstract}

Keywords: Chemical pressure $\cdot\left[\mathrm{Co}(\mathrm{bpy})_{3}\right]^{2+} \cdot\left[\mathrm{Fe}(\mathrm{bpy})_{3}\right]^{2+} \cdot$ Guest-host interaction $\cdot$ Intersystem crossing $\cdot$ Luminescence $\cdot$ Radiationless deactivation $\cdot\left[\mathrm{Ru}(\mathrm{bpy})_{3}\right]^{2+} \cdot$ Spin-crossover

\section{Introduction}

Numerous studies and reviews have dealt with the effects of external pressure on the photophysical properties of transition metal compounds [1]. The key concept is to attribute a specific molecular volume to each electronic state of the complex in question. As a first approximation, an external pressure $p$ changes the zero-point energy difference between two states of this complex by a work term of the form $\mathrm{p} \Delta \mathrm{V}$, where $\Delta \mathrm{V}$ is the difference in molecular volumes between the two states. Thus, the shift of the luminescence from the ${ }^{2} \mathrm{E}$ state of chromium(III) in ruby $\left(\mathrm{Al}_{2} \mathrm{O}_{3}: \mathrm{Cr}^{3+}\right)$ is comparatively small, because the ${ }^{2} \mathrm{E}$ state has the same $\mathrm{t}_{2 \mathrm{~g}}{ }^{3}$ electron configuration as the ${ }^{4} \mathrm{~A}_{2}$ ground state, and therefore the same chemical bonding with the same metal-ligand bond length and the same molecular volume [2]. For iron(II) spin-crossover compounds on the other hand, the difference in bond length of $\sim 0.2 \AA$ between the highspin state and the low-spin state is large, and for these compounds an external pressure typically shifts the thermal spin transition by $20-30 \mathrm{~K}$ per kbar [3].

${ }^{*}$ Correspondence: Prof. A. Hauser

Département de chimie physique

Université de Genève

Bâtiment de Science II

30, quai Ernest-Ansermet

$\mathrm{CH}-1211$ Genève 4

Tel.: +4122702 6559

Fax.: +4122 7026103

E-Mail: andreas.hauser@chiphy.unige.ch
The electronic energies of a given transition metal complex also depend upon the medium. For instance, metal to ligand charge transfer (MLCT) states involving a charge redistribution are very sensitive to the dielectric constant of the solvent [4] Ligand-field states are less influenced by solvent polarity, but they are very much susceptible to external pressure as well as to steric constraints. This is due to the fact that, except for the above-mentioned spin-flip transitions, the equilibrium geometry of excited ligand-field states is generally quite different from that of the ground state [5]. In this contribution, we show how the electronic properties of three classic complexes, namely $\left[\mathrm{Fe}(\mathrm{bpy})_{3}\right]^{2+}, \quad\left[\mathrm{Ru}(\mathrm{bpy})_{3}\right]^{2+}, \quad$ and $\left[\mathrm{Co}(\mathrm{bpy})_{3}\right]^{2+}$ can be tuned in a controlled way by doping them into a series of inert crystalline hosts. The experimental results are discussed in terms of a variation in chemical pressure within the series of host lattices.

\section{The High-Spin $\rightarrow$ Low-Spin Relaxation in $\left[\mathrm{Fe}(\mathrm{bpy})_{3}\right]^{2+}$}

$\left[\mathrm{Fe}(\mathrm{bpy})_{3}\right]^{2+}$ is a typical iron(II) lowspin complex, with all six d-electrons paired up in the $t_{2 g}$ orbitals resulting in a ${ }^{1} \mathrm{~A}_{1}\left(\mathrm{t}_{2 \mathrm{~g}}{ }^{6}\right)$ ground state. The absorption spectrum is dominated by an intense band centered at $530 \mathrm{~nm}$, which is attributed to an MLCT transition [6]. [Fe(bpy $\left.)_{3}\right]^{2+}$ is not too far from the spin-crossover point, and, as indicated in Scheme 1, the corresponding high-spin state with maximum spin multiplicity, the ${ }^{5} \mathrm{~T}_{2}\left(\mathrm{t}_{2 \mathrm{~g}}{ }^{4} \mathrm{e}_{\mathrm{g}}{ }^{2}\right)$ state, has to be at comparatively low energies. The key point to note is that, as in the high-spin state two of the six d electrons reside in the antibonding $e_{g}$ orbitals, the metal-ligand bond length in the high-spin state is substantially longer than in the low-spin state.

In analogy to spin-crossover compounds, the high-spin state can be populated efficiently by pulsed laser excitation into the ${ }^{1}$ MLCT band, followed by an extreme1y fast double intersystem crossing step. Spin-crossover compounds may stay trapped in the light-induced high-spin state for up to several days at cryogenic temperatures [7]. This is due to the energy barrier resulting from the small zero-point energy difference and the large bond length difference between the two states. For low-spin $\left[\mathrm{Fe}(\mathrm{bpy})_{3}\right]^{2+}$ the zero-point energy difference between the two states and therefore the driving force for the relaxation back to the ground state is substantially larger, and as a result the high-spin $\rightarrow$ low-spin relaxation is quite fast even at cryogenic temperatures.

Fig. 1 shows the relaxation rate constants for $\left[\mathrm{Fe}(\mathrm{bpy})_{3}\right]^{2+}$ doped into the series of isostructural host lattices $\left[\mathrm{M}\left(\mathrm{bpy}_{3}\right]\left(\mathrm{PF}_{6}\right)_{2}, \mathrm{M}=\mathrm{Co}, \mathrm{Zn}, \mathrm{Mn}\right.$, and $\mathrm{Cd}$ [8]. As expected from the theory of nonadiabatic multi-phonon relaxation in the strong coupling limit [9], the relaxation proceeds via an almost temperature independent tunneling process below $\sim 50 \mathrm{~K}$ and becomes thermally activated at elevated temperatures. The most striking aspect of the data shown in Fig. 1 is the wide spread of the low temperature tunneling rate constant, ranging from $6.2 \times 10^{3} \mathrm{~s}^{-1}(\tau=162 \mu \mathrm{s})$ for the Cd host to $1.4 \times 10^{6} \mathrm{~s}^{-1}(\tau=720 \mathrm{~ns})$ 


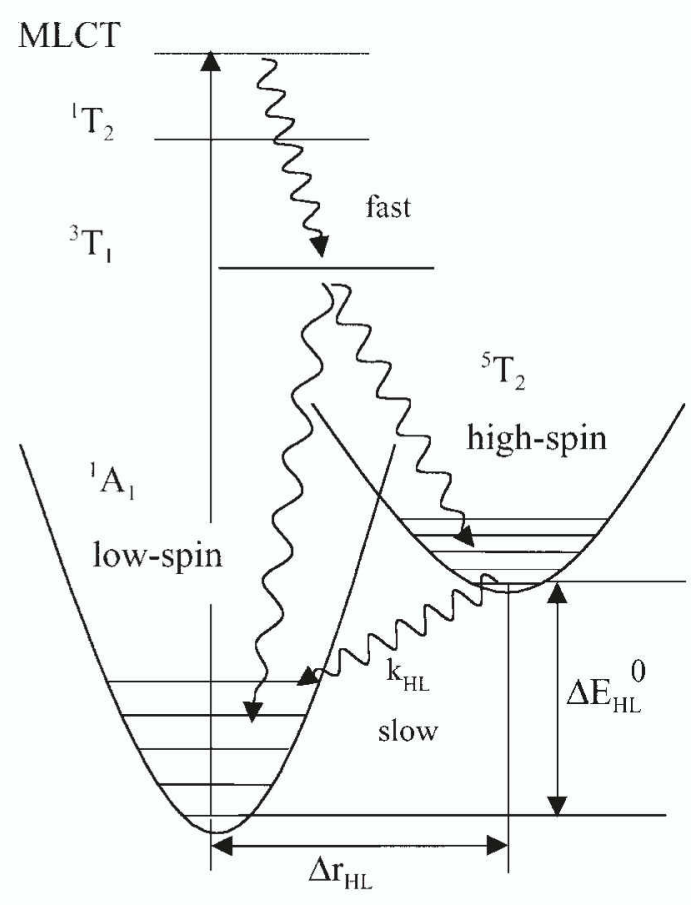

Scheme 1. The electronic structure of $\left[\mathrm{Fe}(\mathrm{bpy})_{3}\right]^{2+}$ with the low-spin ${ }^{1} A_{1}\left(t_{2 g}{ }^{6}\right)$ ground state, excited ligand-field states, and the low-lying MLCT state. Curly arrows indicate the pathway for the extremely efficient radiationless relaxation from higher excited states down to the high-spin ${ }^{5} \mathrm{~T}_{2}\left(\mathrm{t}_{2 \mathrm{~g}}{ }^{4} \mathrm{e}_{\mathrm{g}}{ }^{2}\right)$ state. The subsequent high-spin $\rightarrow$ low-spin relaxation is orders of magnitude slower. The zero-point energy difference $\Delta \mathrm{E}_{\mathrm{HL}}^{0}$ is a function of the surrounding medium.

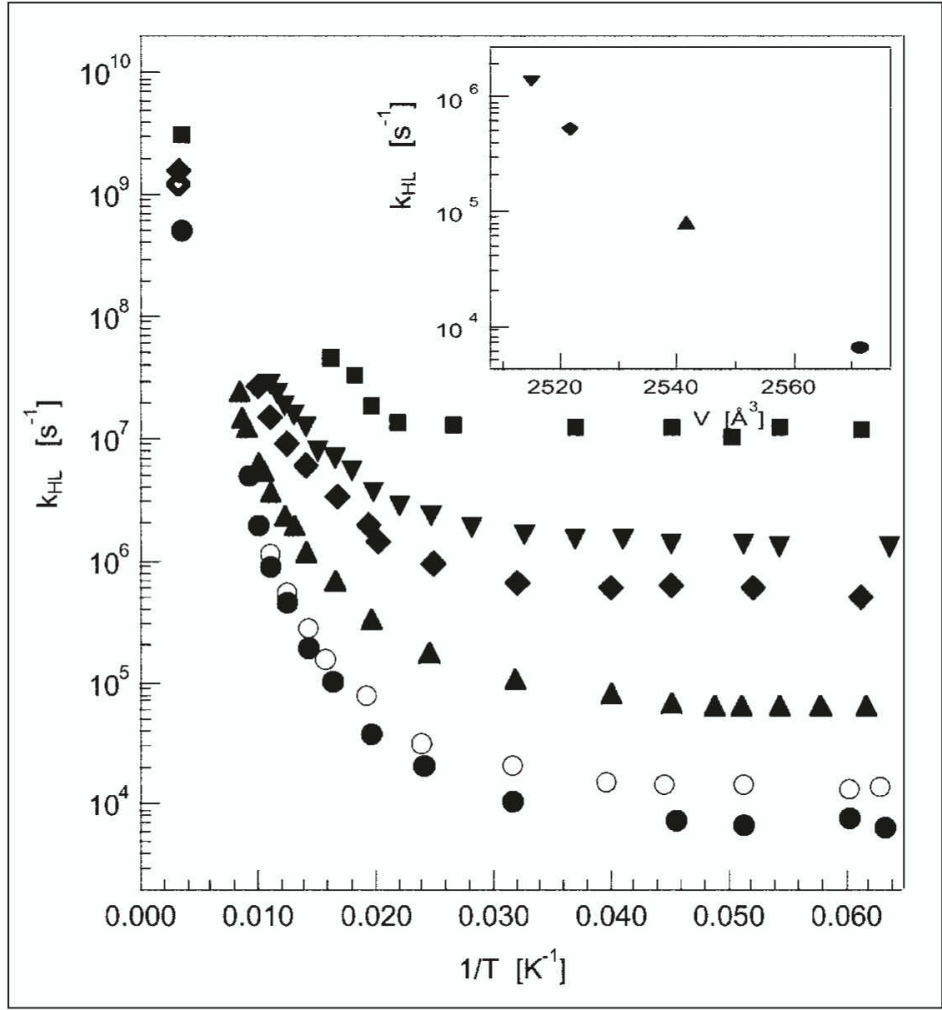

Fig. 1. The high-spin $\rightarrow$ low-spin relaxation rate constant, $\mathrm{k}_{\mathrm{HL}}$, on a logarithmic scale against $1 / \mathrm{T}$ for $\left[\mathrm{Fe}(\mathrm{bpy})_{3}\right]^{2+}$ doped into $\left[\mathrm{M}(\mathrm{bpy})_{3}\right]\left(\mathrm{PF}_{6}\right)_{2}$ $\mathrm{M}=\mathrm{Co}(\boldsymbol{\nabla}), \mathrm{Zn}(\boldsymbol{\bullet}), \mathrm{Mn}(\boldsymbol{\Delta}), \mathrm{Cd}(\boldsymbol{O})$ and into the three-dimensional oxalate network $\left[\mathrm{NaRh}(\mathrm{ox})_{3}\right]\left[\mathrm{Zn}(\mathrm{bpy})_{3}\right](\square)$ at ambient pressure, and for the $\mathrm{Cd}$ host at an external pressure of $1 \mathrm{kbar}(\mathrm{O})$. Insert: The low-temperature tunneling rate constant $\mathrm{k}_{\mathrm{HL}}(\mathrm{T} \rightarrow 0)$ versus the unit cell volume of the isostructural host lattices. for the Co host. Phenomenologically, the low-temperature tunneling rate constant increases with decreasing unit cell volume of the host lattice. As shown in the insert of Fig. 1, $\mathrm{k}_{\mathrm{HL}}$ plotted on a logarithmic scale versus the unit cell volume of the host results in a perfectly linear correlation. The physical interpretation of this result is straight forward. As the cavity provided by the host lattice for the guest becomes smaller and smaller, the high-spin state of the iron(II) complex, with its considerably larger volume as compared to the low-spin state, becomes more and more destabilized. As a result, the driving force for the highspin $\rightarrow$ low-spin relaxation increases and therefore the corresponding rate constant also increases. Thus the effect of the different host lattices on the guest can be viewed as a variation of an internal or chemical pressure. The chemical pressure can be compared to the effect of an external pressure. Fig. 1 includes the relaxation rate constant observed in the Cd host at an external pressure of $1 \mathrm{kbar}$. In the low-temperature tunneling regime, this pressure increases the relaxation rate constant by a mere factor of 2 . Thus, the increase in relaxation rate constant by a factor of $\sim 250$ between the $\mathrm{Cd}$ and the Co host indicates an internal pressure variation corresponding to $\sim 8 \mathrm{kbar}$. By doping $\left[\mathrm{Fe}(\mathrm{bpy})_{3}\right]^{2+}$ into the even more confining host lattice of the oxalate network $\left[\mathrm{Zn}(\mathrm{bpy})_{3}\right]\left[\mathrm{NaRh}(\mathrm{ox})_{3}\right]$ the chemical pressure can be increased still further, and the low-temperature tunneling rate constant increases by another order of magnitude to $1.3 \times 10^{7} \mathrm{~s}^{-1}(\tau=81 \mathrm{~ns})$. The total shift in zero-point energy difference between the high-spin and the low-spin state from the $\mathrm{Cd}$ host to the oxalate network is estimated to be of the order of $2000 \mathrm{~cm}^{-1}(24 \mathrm{~kJ} /$ mole $)$.

At room temperature the relaxation rate constant for the investigated systems falls into the comparatively narrow range of 0.5 to $3 \times 10^{9} \mathrm{~s}^{-1}(\tau=0.35-2 \mathrm{~ns})$. At elevated temperatures, tunneling proceeds via thermally populated vibrational levels of the high-spin state, and in the high-temperature limit the variation of the driving force has less of an effect on the rate constant than in the low-temperature tunneling region.

\section{The Quencher State in $\left[\mathrm{Ru}(\mathrm{bpy})_{3}\right]^{2+}$}

As for the iron(п) complex, the ground state of $\left[\mathrm{Ru}(\mathrm{bpy})_{3}\right]^{2+}$ is the diamagnetic ${ }^{1} \mathrm{~A}_{1}\left(\mathrm{t}_{2 \mathrm{~g}}{ }^{6}\right)$ state. As depicted in Scheme 2, the lowest excited state, from which the famous orange luminescence originates, is an MLCT state having a triplet character [10]. At low temperatures, the luminescence 


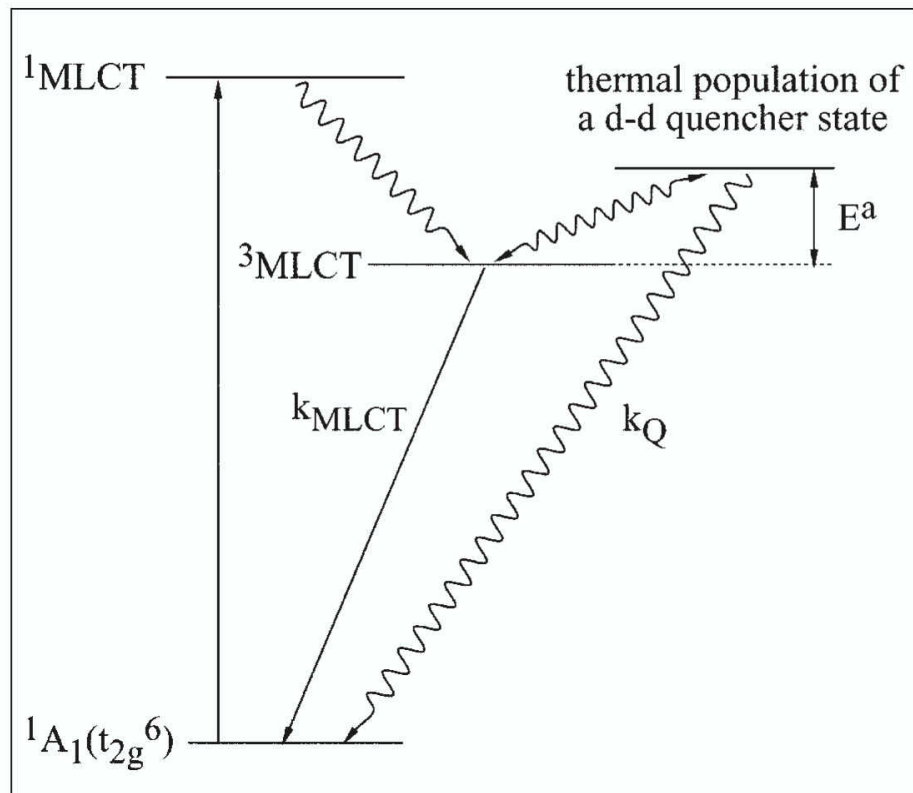

Scheme 2. The electronic structure of $\left[\mathrm{Ru}(\mathrm{bpy})_{3}\right]^{2+}$. The much higher ligand-field strength as compared to $\left[\mathrm{Fe}(\mathrm{bpy})_{3}\right]^{2+}$ pushes the excited ligand-field states to energies which are above the energy of the lowest excited ${ }^{3} \mathrm{MLCT}$ state. As a result, there is luminescence from this ${ }^{3} \mathrm{MLCT}$ state. At elevated temperatures the luminescence thermally activated quenching sets in. This quenching is thought to proceed via the thermal population of close lying ligand-field states.

quantum efficiency is quite high, but at elevated temperatures the luminescence becomes thermally quenched. This behavior has been interpreted as being due to a close lying d-d state which becomes thermally populated at elevated temperatures, thereby quenching the ${ }^{3}$ MLCT luminescence via non-radiative processes [11]. To date there is no hard experimental evidence for the assignment of this state, but it is generally assumed to be a triplet ligand-field state belonging to the $\mathrm{t}_{2 \mathrm{~g}}{ }^{5} \mathrm{e}_{\mathrm{g}}{ }^{1}$ configuration.

Fig. 2 shows the luminescence lifetime of the ${ }^{3}$ MLCT state of $\left[\mathrm{Ru}(\mathrm{bpy})_{3}\right]^{2+}$ doped into the two above-mentioned crystalline hosts, $\left[\mathrm{M}(\mathrm{bpy})_{3}\right]\left(\mathrm{PF}_{6}\right)_{2}, \mathrm{M}=\mathrm{Cd}$, and $\mathrm{Zn}$, as well as into the oxalate network $\left[\mathrm{Zn}(\mathrm{bpy})_{3}\right]\left[\mathrm{NaAl}(\mathrm{ox})_{3}\right]$ as a function of temperature between 10 and $520 \mathrm{~K}$. Below $180 \mathrm{~K}$ all curves follow the behavior reported for $\left[\mathrm{Ru}(\mathrm{bpy})_{3}\right]^{2+}$ in a poly-metacrylate glass [10]. For the $\left[\mathrm{Cd}(\mathrm{bpy})_{3}\right]\left(\mathrm{PF}_{6}\right)_{2}$ host, thermal quenching sets in at $\sim 180 \mathrm{~K}$, for $\left[\mathrm{Zn}(\mathrm{bpy})_{3}\right]\left(\mathrm{PF}_{6}\right)_{2}$ at $\sim 270 \mathrm{~K}$, and for the oxalate network $\left[\mathrm{Zn}(\mathrm{bpy})_{3}\right]\left[\mathrm{NaAl}(\mathrm{ox})_{3}\right]$ at $\sim 380 \mathrm{~K}$. In addition, under an external pressure of $30 \mathrm{kbar}$, the $\left[\mathrm{Ru}(\mathrm{bpy})_{3}\right]^{2+}$ luminescence in the oxalate network is not quenched all the way up to $520 \mathrm{~K}$ ! The quenching temperature thus follows the increasing chemical pressure, and in the oxalate network, an additional external pressure removes the quencher state altogether. Both chemical and physical pressure thus shift the quencher state to higher energies. d-d excited state. $\mathrm{k}_{\mathrm{Q}}(\mathrm{T})$, according to [11]

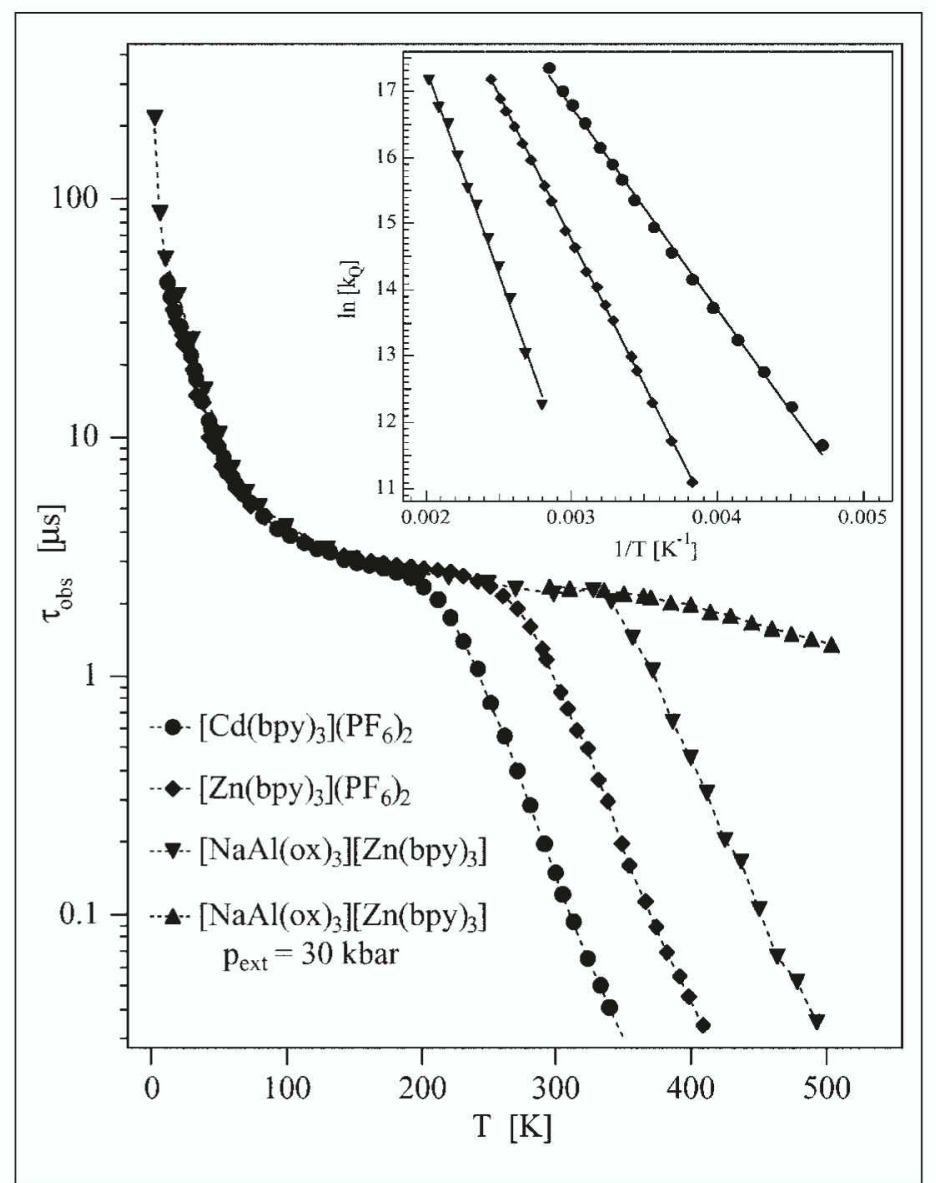

Fig. 2. Excited state lifetimes (on a logarithmic scale) versus temperature for $\left[R u(b p y)_{3}\right]^{2+}$ doped into $\left[\mathrm{M}(\mathrm{bpy})_{3}\right]\left(\mathrm{PF}_{6}\right)_{2}(\mathrm{M}=\mathrm{Cd}, \mathrm{Zn})$ and into the three-dimensional oxalate network $\left[\mathrm{Zn}(\mathrm{bpy})_{3}\right]\left[\mathrm{NaAl}(\mathrm{ox})_{3}\right]$ at ambient pressure. For the latter system the lifetime at an external pressure of $10 \mathrm{kbar}$ is included. Insert: The thermal quenching rate constant $\mathrm{k}_{\mathrm{Q}}$ plotted on a logarithmic scale versus $1 / \mathrm{T}$.

It therefore has a larger molecular volume than the ${ }^{3}$ MLCT state, as expected for a

The observed relaxation rate constant, $\mathrm{k}_{\mathrm{obs}}(\mathrm{T})$, can be expressed as the sum of the direct relaxation rate constant of the ${ }^{3} \mathrm{MLCT}$ state, $\mathrm{k}_{\mathrm{MLCT}}(\mathrm{T})$, comprising both radiative and non-radiative processes, and the thermally activated quenching process

$$
\mathrm{k}_{\mathrm{obs}}(\mathrm{T})=\mathrm{k}_{\mathrm{MLCT}}(\mathrm{T})+\mathrm{k}_{\mathrm{Q}}(\mathrm{T})=\mathrm{k}_{\mathrm{MLCT}}(\mathrm{T})+\mathrm{A} \cdot \mathrm{e}^{-\mathrm{Ea} / \mathrm{kBT}}
$$

The temperature dependence of the direct decay at elevated temperatures is accessible experimentally as the lifetime of the $\left[\mathrm{Ru}(\mathrm{bpy})_{3}\right]^{2+}$ luminescence in $\left[\mathrm{Zn}(\mathrm{bpy})_{3}\right]\left[\mathrm{NaA} 1(\mathrm{ox})_{3}\right]$ under the external pressure of 30 kbar. $k_{O}(T)$ can thus be extracted from the experimental data. The insert of Fig. 2 shows plots of $\ln \left[\mathrm{k}_{\mathrm{Q}}(\mathrm{T})\right]$ versus $1 / \mathrm{T}$ for the three host lattices. They are all perfectly linear with activation energies $\mathrm{E}^{\mathrm{a}}$ of $2110(30) \mathrm{cm}^{-1}$ for $\left[\mathrm{Cd}(\mathrm{bpy})_{3}\right]\left(\mathrm{PF}_{6}\right)_{2}$,
$3045(20) \mathrm{cm}^{-1}$ for $\left[\mathrm{Zn}(\mathrm{bpy})_{3}\right]\left(\mathrm{PF}_{6}\right)_{2}$, and $4310(80) \mathrm{cm}^{-1}$ for $\left[\mathrm{Zn}(\mathrm{bpy})_{3}\right]\left[\mathrm{NaAl}(\mathrm{ox})_{3}\right]$, respectively. Such a large variation in activation energy, as compared to the rather small shift of the ${ }^{3}$ MLCT luminescence, indicates that the molecular volume of $\left[\mathrm{Ru}(\mathrm{bpy})_{3}\right]^{2+}$ in the quencher state is substantially larger than in the luminescent state. As the ${ }^{3}$ MLCT state equilibrium geometry is not very much different from the ground state geometry, it can be con- 
cluded that the molecular volume of the quencher state is also very much larger than the one of the ${ }^{1} \mathrm{~A}_{1}\left(\mathrm{t}_{2 \mathrm{~g}}{ }^{6}\right)$ ground state. Indeed the variation of the activation energy is of the same order of magnitude as for the zero-point energy difference between the high-spin and the low-spin state in the corresponding iron(II) system discussed in section 2 . Thus the commonly assumed assignment of the d-d quencher state to the lowest energy triplet state originating from the $\mathrm{t}_{2 \mathrm{~g}}{ }^{5} \mathrm{e}_{\mathrm{g}}{ }^{1}$ configuration is not conclusive. The large variation of the activation energy on the surrounding medium indicates that it could also be the quintet high-spin state originating from the $\mathrm{t}_{2 \mathrm{~g}}{ }^{4} \mathrm{e}_{\mathrm{g}}{ }^{2}$ configuration. Naturally further experiments are needed to substantiate this tentative reassignment of the d-d quencher state. It is, however, corroborated by a number of experimental observations. It explains a) the high quantum efficiency of photochemical ligand substitution for $\left[\mathrm{Ru}(\mathrm{bpy})_{3}\right]^{2+}$ in solution, b) as to why for $\left[\mathrm{Ru}(\mathrm{bpy})_{3}\right]^{2+}$ and its numerous derivatives there is not a single case for which luminescence from a d-d state is observed, c) the dependence of the luminescence quantum yield on the second coordination sphere and on minor chemical changes in the ligand system.

\section{Turning $\left[\mathrm{Co}(\mathrm{bpy})_{3}\right]^{2+}$ into a Spin-Crossover Complex}

In contrast to the iron(II) complex, $\left[\mathrm{Co}(\mathrm{bpy})_{3}\right]^{2+}$ generally is a typical $\mathrm{d}^{7}$ highspin complex with a ${ }^{4} \mathrm{~T}_{1}\left(\mathrm{t}_{2 \mathrm{~g}} \mathrm{e}_{\mathrm{g}}{ }^{1}\right)$ ground state [12]. This is also the case for $\left[\mathrm{Co}(\mathrm{bpy})_{3}\right]^{2+}$ as cation in the three-dimensional network of composition $\left[\mathrm{Co}(\mathrm{bpy})_{3}\right]$ $\left[\mathrm{NaCr}(\mathrm{ox})_{3}\right]$. Its magnetic susceptibility plotted as the product $\chi \mathrm{T}$ versus temperature is shown in Fig. 3 together with $\chi \mathrm{T}$ of $\left[\mathrm{Zn}(\mathrm{bpy})_{3}\right]\left[\mathrm{NaCr}(\mathrm{ox})_{3}\right]$ for reference. After subtracting the spin-only contribution of $\mathrm{S}=3 / 2$ from chromium(III), it shows the typical behavior of high-spin $\left[\mathrm{Co}(\mathrm{bpy})_{3}\right]^{2+}$ with a strong orbital contribution to the magnetic moment. However, $\left[\mathrm{Co}(\mathrm{bpy})_{3}\right]^{2+}$ is not too far away from the spin-crossover point. As indicated in Scheme 3, the zeropoint energy of the corresponding low-spin state, the ${ }^{2} \mathrm{E}\left(\mathrm{t}_{2 \mathrm{~g}}{ }^{6} \mathrm{e}_{\mathrm{g}}{ }^{1}\right)$ state, is at only slight- ly higher energy than the ground state. The strategy to push $\left[\mathrm{Co}(\mathrm{bpy})_{3}\right]^{2+}$ to become a spin-crossover complex is to reduce the size of the cavity provided by the host. This is easily achieved by substituting $\mathrm{Li}$ for $\mathrm{Na}$ in the three-dimensional network. That the strategy actually works is borne out by the magnetic susceptibility of $\left[\mathrm{Co}(\mathrm{bpy})_{3}\right]$ $\left[\mathrm{LiCr}(\mathrm{ox})_{3}\right]$ also shown in Fig. 3 [13]. As expected for $\mathrm{a}^{2} \mathrm{E}$ state, at low temperatures the contribution of $\left[\mathrm{Co}(\mathrm{bpy})_{3}\right]^{2+}$ to $\chi \mathrm{T}$ corresponds to the spin-only value for $S=1 / 2$. Because the energy difference between the high-spin and the low-spin state is not very large, a thermal, entropy-driven population of the high-spin state is observed with increasing temperature. The value of $\chi \mathrm{T}$ at room temperature corresponds to a fraction of complexes in the high-spin state of $\sim 75 \%$.

\section{Concluding Remarks}

Lattice forces can be substantial. Just by substituting the metal ion of the inert hosts, the effect of the chemical difference in pres-
Fig. 3. Magnetic susceptibilities of polycrystalline samples of $\left[\mathrm{Co}(\mathrm{bpy})_{3}\right]\left[\mathrm{NaCr}(\mathrm{ox})_{3}\right](\mathbf{\Delta})$, $\left[\mathrm{Co}(\mathrm{bpy})_{3}\right]\left[\mathrm{LiCr}(\mathrm{ox})_{3}\right] \quad(\mathbf{O})$, and $\left[\mathrm{Zn}(\mathrm{bpy})_{3}\right]$ [NaCr(ox)3] (অ), plotted as $\chi^{\top}$ versus temperature (adapted from [13])

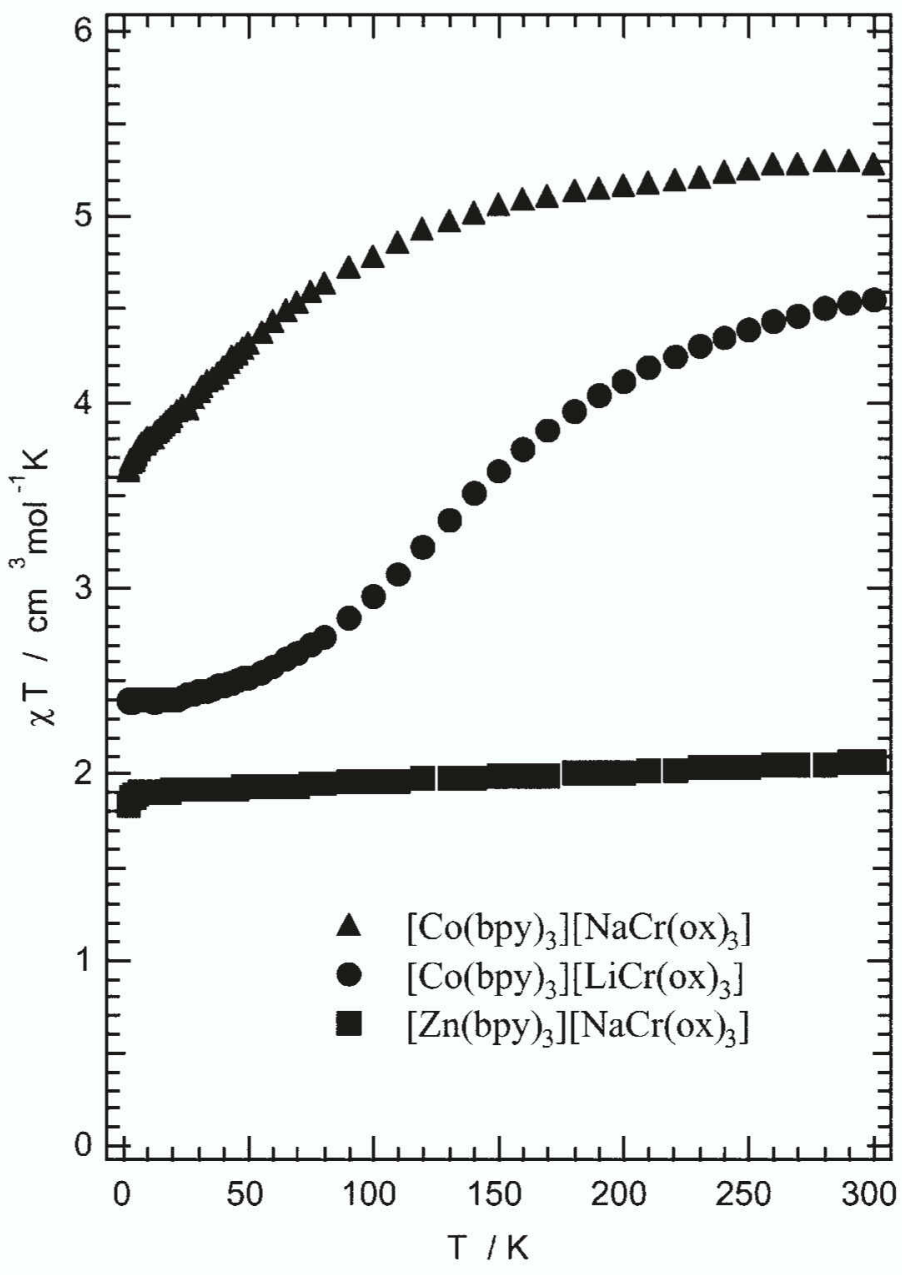




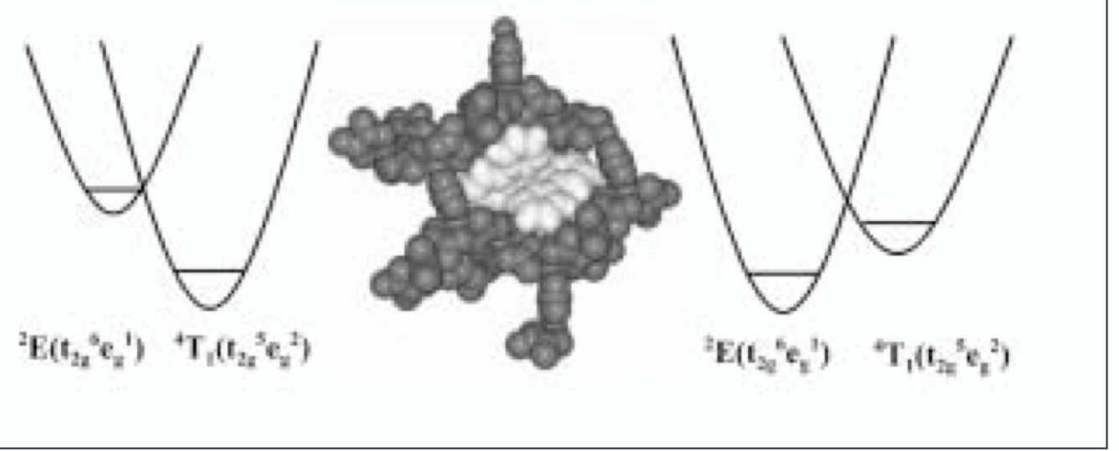

Scheme 3. The electronic structure of $\left[\mathrm{Co}(\mathrm{bpy})_{3}\right]^{2+}$ with a high-spin ground state and the effect of chemical pressure provided by the cavities of the oxalate network which destabilises the high-spin state.

sure can be equivalent to several kbar of external pressure. The three examples chosen here are instructive in showing quantitatively by how much energy levels actually shift, and how dramatic the effect of seemingly minor chemical changes in the second coordination sphere can be. They result in a) several orders of magnitude variation in the rate constant of the high-spin $\rightarrow$ lowspin relaxation in $\left.\left[\mathrm{Fe}(\mathrm{bpy})_{3}\right]^{2+}, \mathrm{b}\right)$ a large variation in activation energy for the thermal quenching of the luminescence in $\left[\mathrm{Ru}(\mathrm{bpy})_{3}\right]^{2+}$, suggesting an alternative assignment of the quencher state, and c) outright crossover of the electronic ground state for $\left[\mathrm{Co}(\mathrm{bpy})_{3}\right]^{2+}$. For all three, the importance lies in the fact that ground and excited states have very different equilibrium geometries and therefore respond differently to external perturbations.

Of course, the concept of internal pressure is very crude and constitutes only a first approximation to the complex problem of guest-host interactions. Advances in computational power should lead to a better understanding of such interactions in the not too distant future.

\section{Acknowledgements}

We thank P. Brodard for room temperature pico-second work on the iron(II) systems, G. Bernardinelli for the X-ray work on the host lattices, R. Toomey and I.Y. Chan for the pressure work on and S. Decurtins for the picture of the oxalate network. This work was financially supported by the Swiss National Science Foundation.
[1] a) J.K. Grey, I.S. Butler, Coord. Chem. Rev. 2000, 219, 713. b) K.L. Bray, Topics in Current Chemistry 2001, 213, Springer Verlag, Berlin.

[2] H.G. Drickamer, C.W. Frank, 'Electronic Transitions and the High Pressure Chemistry and Physics of Solids', John Wiley \& Sons, New York, 1973.

[3] G.F. Imbusch, W.M. Yen, Springer Ser. Opt. Sci. 1987, 54, 'Lasers, Spectroscopy and New Ideas'.

[4] a) J.V. Caspar, T.J. Meyer, J.Amer. Chem. Soc. 1983, 105, 5583; b) N.S. Hush, J.R. Reimers, Coord. Chem. Rev. 1987, 177, 37.

[5] H.L. Schläfer, G. Gliemann, 'Einführung in die Ligandenfeldtheorie', Akad Verlagsgesellschaft, Wiesbaden, 1980.

[6] J. Ferguson, F. Herren, Chem. Phys. 1983, 76,45 .

[7] a) P. Gütlich, A. Hauser, H. Spiering, Angew. Chem. Int. Ed. Engl. 1994, 33, 2024; b) A. Hauser, J. Jeftic, H. Romstedt, R. Hinek, H. Spiering, Coord. Chem. Rev. 1999, 190-192, 471.

[8] S. Schenker, A. Hauser, W. Wang, I. Y. Chan, Chem. Phys. Letters 1998, 297, 281.

[9] E. Buhks, G. Navon, M. Bixon, J Jortner, J. Amer. Chem. Soc. 1980, 102, 2918.

[10] R.W. Harrigan, G.D. Hager, G.A. Crosby, Chem. Phys. Lett. 1973, 21, 487.

[11] J. Van Houten, R.J. Watts, J. Am. Chem. Soc. 1976, 98, 4853.

[12] A.B.P. Lever, 'Inorganic electronic spectroscopy', 2nd ed., Elsevier, Amsterdam, 1984.

[13] R. Sieber, S. Decurtins, H. StoeckliEvans, C. Wilson, D. Yufit, J.A.K. Howard, S.C. Capelli, A. Hauser, Chem. Eur. J. 2000, 6, 361. 